TRABAJO Y TRABAJADORES:

RED LATINOAMERICANA

\title{
DEBATES E INTERVENCIONES
}

\section{Historias del trabajo y de la prostitución en América Latina: diálogos posibles}

\author{
Cristiana Schettini
}

Consejo Nacional de Investigaciones Científicas y Técnicas, Argentina crischettini@gmail.com

$$
\text { Paulo Drinot }
$$

University College London, Reino Unido paulo.drinot@ucl.ac.uk

\section{Ana Carolina Gálvez Comandini}

Universidad Metropolitana de Ciencias de la Educación, Chile comandinig@gmail.com

\section{PATRICIO SimonetTo}

Centro de Investigaciones en Estudios y Políticas de Género, Consejo Nacional de Investigaciones Científicas y Técnicas, Universidad Nacional de Tres de Febrero, Argentina patriciosimonetto@gmail.com

$$
\text { BEATRIZ KUSHNIR }
$$

Arquivo Geral da Cidade do Río de Janeiro, Brasil

biakushnir@gmail.com 


\section{Presentación}

\section{Cristiana Schettini}

¿Qué hace una prostituta? Las muchas actividades y vínculos que involucraron sexo y dinero en el pasado fueron pensados con considerable frecuencia en términos laborales. Por eso, el desafío de pensar la historia social de la prostitución en diálogo con la historia del trabajo no debería tomarnos de sorpresa. Desde la arcaica expresión que designa la prostitución como "la profesión más antigua del mundo" hasta los encendidos debates recientes sobre si la actividad sería un "trabajo como cualquier otro", pasando por el amplio campo semántico asociado a la esclavitud y sus connotaciones racializadas, y las percepciones de las propias mujeres y sus familias sobre lo que hacían, la prostitución fue y sigue siendo vista cerca del mundo del trabajo.

Cuando empezaron a organizarse colectivamente en movimientos sociales a fines del siglo XX, en especial en América Latina, las prostitutas mismas optaron mayoritariamente por la denominación de trabajadoras sexuales. La reivindicación de una identidad laboral respaldaba el reclamo por derechos básicos, que incluían garantías de integridad física, y acceso a la salud y jubilación. Para muchas mujeres, entonces, inscribirse en el mundo del trabajo se volvió una manera de hacer frente a estigmas morales fuertemente arraigados en la sociedad, incluso en sectores del movimiento feminista. ${ }^{1}$

Esta sección parte de una indagación sobre qué puede contribuir el acúmulo de estudios sobre América Latina a la reflexión historiográfica sobre trabajo y sexo comercial. Para eso, reúne autoras y autores que escribieron sobre prostitución en Chile, Brasil, Argentina y Perú entre fines del siglo XIX y fines del siglo XX. ${ }^{2}$ Se les invitó a reflexionar sobre las conexiones y tensiones entre las historias de la prostitución y los mundos del trabajo a partir de sus experiencias de investigación.

1 Kamala Kempadoo y Jo Doezema (ed.), Global Sex Workers: rights, resistance and redefinition (New York: Routledge, 1998).

2 Paulo Drinot, The Sexual Question: a history of prostitution in Peru, 1850-1950s (Cambridge: Cambridge University Press, 2020); Patricio Simonetto, El dinero no es todo: Compra y venta de sexo en la Argentina del siglo XX (Buenos Aires: Biblos, 2019); Beatriz Kushnir, Baile de Máscaras: mulheres judias e prostituição: as polacas e suas associações de ajuda mutua (Rio de Janeiro: Imago, 1996); Ana Gálvez Comandini, Mujeres públicas: experiencia e identidad de las prostitutas en Santiago de Chile, 1896-1940 (Universidad de Chile: Tesis Doctoral, 2018). 
Los caminos recorridos por la historia social para pensar las conexiones entre prostitución y trabajo fueron más tortuosos y lentos que los acercamientos desde otras disciplinas. Durante muchas décadas, las historias sobre prostitución estuvieron más próximas de la historia cultural y social de la ciudad, de la sexualidad y del control social que de la historia del trabajo propiamente. Sin embargo, ya en 1980, el estudio pionero de Judith Walkowitz revisó la mirada victimizante sobre las prostitutas victorianas hasta entonces predominante en la historiografía y en el sentido común- al contarnos una historia de las políticas públicas sobre la prostitución en dos ciudades portuarias inglesas, centrada en la agencia histórica de las prostitutas. ${ }^{3}$ Atenta a la intersección entre clase y género, ella consideró la experiencia de la prostitución a la luz de la experiencia más amplia de las mujeres de la clase trabajadora y de las estrategias de sobrevivencia de los pobres en Inglaterra. Esta perspectiva también la llevó a explorar las confluencias y tensiones entre el accionar de las prostitutas y el de las feministas, contribuyendo así a una reflexión crítica sobre los debates feministas sobre prostitución que se intensificaron en las últimas décadas. ${ }^{4}$

Diez años después, Luise White publicó su renovadora historia de la prostitución en Nairobi. ${ }^{5}$ El desplazamiento geográfico hacia una ciudad africana, y principalmente el empleo de las preguntas propias de la historia social del trabajo con una mirada feminista, la inspiraron a replantear muchos lugares comunes de las historias de la prostitución centradas en casos europeos. La perspectiva de las propias prostitutas sobre qué hacían le permitió desechar la mirada moralista y victimizante, reiterada por la historiografía producida en el Atlántico Norte, a favor de un argumento sobre la centralidad de las prostitutas kenianas para la comprensión del trabajo, de la acumulación de capital y de la transmisión de riqueza en procesos migratorios que conectaban mundos rurales y urbanos, economías domésticas y mercados de trabajo en el siglo XX. La prostitución, entonces, pasaba a ser un tema clave para abordar la economía política en clave de género.

En estudios como el de Walkowitz y el de White, el comercio sexual se volvió una forma de articular una diversidad de temas habituales para la historia social del trabajo, tales como la organización familiar, la división sexual del

3 Judith Walkowitz, Prostitution and Victorian Society: women, class and the state (Cambridge, U.K.: Cambridge University Press, 1980).

4. Judith Walkowitz, "Politics of prostitution and sexual labour", History Workshop Journal, 82, 1, (2016): 188-198.

5 Luise White, The Comforts of Home: prostitution in Colonial Nairobi (Chicago: Univ. of Chicago Press, 1991). 
trabajo, la migración y la comunidad obrera. Historias sociales con prostitutas llaman la atención para lo que se ha considerado trabajo y lo que ha quedado afuera de esta definición en diferentes momentos, y contribuyen a renovar la atención sobre lo que la tradición feminista marxista solía identificar como el trabajo de reproducción de la fuerza laboral. En las últimas décadas, muchos estudios se enfocaron en la agencia histórica de las prostitutas, en especial a través del debate sobre el consentimiento, la coacción y los sentidos de la explotación sexual, aunque no siempre tomando el trabajo como un eje articulador explícito. ${ }^{6}$

Los recortes espaciales desempeñan un rol central en los movimientos de la historiografía sobre la prostitución. En su libro, White sostiene que parte de la novedad de su argumento es resultado de una investigación sobre una ciudad africana en la que burdeles y proxenetas eran desconocidos. Su análisis del caso africano desnaturalizó lo que la historiografía producida en y sobre el atlántico norte consideraba habitual, desmontándola en su status de parámetro implícito para el resto del mundo.

En los cuatro textos aquí reunidos, la idea de que la prostitución es una actividad contrasta con la noción ampliamente extendida en las fuentes de que la prostitución implica una identidad, un destino, o una fatalidad para muchas mujeres. Quizás este sea uno de los impactos más inmediatos de la inspiración de la historia del trabajo para una historia social de la prostitución: la posibilidad de plantear preguntas que permitan insertar la prostitución en un continuum de otras actividades que desempeñaban las mujeres vistas como prostitutas. En muchos contextos, el trabajo del sexo es parte de una miríada de trabajos domésticos, más o menos remunerados, en los cuales vínculos afectivos y económicos eran establecidos.

Una segunda dimensión destacable en todos los textos se refiere a la interacción entre la clase, el género, la moralidad sexual, los procesos de racialización, y las peculiaridades de los casos analizados. En su contribución, Paulo Drinot argumenta que lo que hacen las prostitutas en las calles de Lima puede ofrecernos una mirada sobre la formación del Estado peruano arraigada en las relaciones sociales, en la raza y en negociaciones cotidianas.

6 Timothy J. Gilfoyle, "Prostitutes in history: from parables of pornography to metaphors of modernity", The American Historical Review, 104, 1, (1999):117141; Lex Heerma van Voss, "The Worst class of workers: migration, labor relations and living strategies of prostitutes around 1900" in Working on labor: essays in honor of Jan Lucassen, Marcel Van der Linden y Leo Lucassen (eds.) (Leiden: Brill, 2012), 153-170; Magaly Rodríguez García, Lex Heerma van Voss y Elise van Nederveen Meerkerk, Selling Sex in the City: a global history of prostitution, 1600-2000s (Leiden: Brill, 2017), 653-861. 
Tanto él como Ana Carolina Galvez Comandini llaman la atención sobre las interacciones entre procesos de racialización en las historias de la prostitución en Chile y en Perú. Para Drinot, la producción de alteridades racializadas, sea hacia la inmigración asiática o a la población indígena local, es parte insoslayable de la producción de la cuestión sexual en Perú.

A su vez, Comandini explora los diversos resultados que la amplia circulación de las historias racializadas de trata de blancas producían en el contexto chileno. Aunque Chile no estuviera integrado en el espacio atlántico que alimentaba esas narrativas, las historias de trata a comienzos del siglo XX generaron en el país trasandino una arena judicial de disputas sobre los sentidos de la inducción, coacción y autonomía en el desplazamiento de prostitutas y en las actividades que ellas hacían. Para ambos autores, dimensiones de resistencia, acomodación y autonomía se expresan en el accionar de las mujeres en ámbitos estatales y judiciales, registrados en documentaciones oficiales.

Las contribuciones de Beatriz Kushnir y Patricio Simonetto, de formas muy distintas, traen a un primer plano una reflexión sobre los sentidos políticos de la investigación histórica sobre el tema. Simonetto parte de su distanciamiento hacia las acciones de varones de otros tiempos para producir un efecto de extrañamiento y encauzar su interpretación sobre los sentidos de masculinidades negociadas por varones que establecían diferentes vínculos con las prostitutas, entre los cuales el de comprar sexo. Esta mirada situada y atenta a la dimensión moral en las definiciones contemporáneas de la clase trabajadora en la Argentina le permite observar jóvenes consumidores de sexo que quizás estuviesen más a gusto en la interacción con agentes policiales que con líderes sindicales.

El trabajo de Beatriz Kushnir es inspirado en su compromiso hacia la memoria de mujeres y varones judíos que se organizaron en asociaciones de ayuda mutua para enfrentar el estigma social de la prostitución y de la extranjería en Brasil. La historia de esa experiencia organizativa sigue siendo urgente cada vez que amenazas y descalificaciones vuelven a amenazar la preservación de sus cementerios y su memoria colectiva. Este abordaje integra de forma pionera la prostitución a la experiencia colectiva de trayectorias migratorias y asociativas, comunes a otros colectivos más conocidos de la historia del trabajo.

Al tratar de temáticas tan diversas como experiencias asociativas, sociabilidades masculinas, políticas sexuales y la organización social del sexo remunerado en diversos contextos latinoamericanos, estos estudios indican la potencialidad de la historia del trabajo para muchas historias de la 
prostitución y viceversa. Lejos de traducirse en una intervención en el polarizado debate sobre si y cuánto de lo que hacen las prostitutas es trabajo, o si las prostitutas del pasado se veían o no como trabajadoras, estas reflexiones subrayan la potencialidad de las preguntas de la historia del trabajo para una inserción de las prostitutas y sus clientes, amantes y familiares en las vidas migratorias, afectivas, de producción y de transmisión de riqueza.

$\mathrm{Al}$ mismo tiempo, las evidencias y argumentos que estos estudios proponen a partir de casos latinoamericanos pueden ser de gran interés para las agendas actuales de la historia del trabajo en distintas latitudes. Saber qué hacían las mujeres que vendían sexo y los varones que consumían sexo en otros tiempos y lugares puede contribuir al debate en curso sobre la propia definición de trabajo y sus exclusiones, sobre las dificultades de trazar fronteras entre formas de coacción laboral aceptables e inaceptables y sobre estrategias metodológicas para integrar procesos de racialización a una mirada de género sobre la experiencia social en el pasado.

Por todo eso, la pregunta sobre qué hacían las prostitutas en otros tiempos puede llevarnos a contemplar aristas inesperadas que aparecen cuando el cruce de líneas historiográficas que solían andar separadas se reúnen en el intento de comprender la experiencia histórica en su multiplicidad de sentidos. Los diálogos entre los dos campos pueden ayudarnos a desvelar las dificultades y quizás las posibilidades de luchas más solidarias por derechos más inclusivos. 


\section{De la cuestión social a la cuestión sexual}

\section{Paulo Drinot}

A fines de la década de 1990, mientras me abría paso entre los documentos y legajos, en gran parte desorganizados, de la serie de la Prefectura de Lima que se encuentran en el Archivo General de la Nación, me detuve en seco.* Estaba buscando y encontrando informes policiales sobre actividades sindicales, panfletos confiscados del Partido Comunista y listas de militantes del APRA encarcelados. Pero pronto me encontré distraído y fascinado por un tipo de documento muy diferente. Estos documentos eran cartas escritas por prostitutas, o en su nombre, y enviadas a las autoridades, en particular al Prefecto de Lima. En estas cartas, las mujeres generalmente se quejaban de que se les había ordenado trasladar su burdel a diferentes partes de la ciudad, habían sido multadas por incumplir las regulaciones que habían sido impuestas por las autoridades, habían sido sometidas a exámenes médicos y que la policía había tratado a algunas mujeres mejor que a otras. Sabía que tales documentos eran raros, incluso extremadamente raros.

Aunque debería haberme concentrado en los informes policiales sobre las actividades sindicales, comencé a tomar notas. Mi libro The Sexual Question: A History of Prostitution in Peru, 1850s-1950s surgió de ese momento de indisciplina archivística. Esta conexión documental, algo superficial, es uno de los puentes entre la investigación que resultó en mi primer libro, The Allure of Labor: Workers, Race, and the Making of the Peruvian State, que se enfocaba en la cuestión social en el Perú a comienzos de siglo XX, y la que llevó a mi segundo libro, un estudio sobre la historia de la prostitución en el Perú. ${ }^{7}$ Quiero contestar a la invitación a participar en este 'Debate Redlatt sobre prostitución e historia social del trabajo' con una reflexión sobre cómo el marco conceptual que empleé en mi primer libro, para entender de qué modo se abarcó la cuestión social en el Perú de comienzos de siglo XX, me sirvió para entender cómo se constituyeron las políticas hacia la prostitución en el mismo periodo. Más que una historia social del trabajo, mi primer libro es una historia del 'Estado obrero' que se forma en respuesta a la cuestión social. Al mismo tiempo, más que una historia social de la prostitución, mi

* Este texto se basa en, y adapta, las ideas de la introducción de mi libro, The Sexual Question: A History of Prostitution in Peru, 1850s-1950s (Cambridge: Cambridge University Press, 2020).

7 Paulo Drinot, The Allure of Labor: Workers, Race and the Making of the Peruvian State (Durham: Duke University Press, 2011). 
segundo libro es una historia del 'Estado sexual', del Estado que se forma en respuesta a lo que llamo la cuestión sexual.

Aunque el arco narrativo de mi segundo libro sigue el ascenso y el declive del reglamentarismo y el aparente triunfo del abolicionismo como paradigmas que rigen la gestión de la prostitución en el Perú, y que se manifiestan más claramente en la creación del barrio rojo de Lima -el famoso Huatica de la novela La ciudad y los perros de Mario Vargas Llosa- en 1928 y su clausura en 1956, mi objetivo fue explorar un conjunto más amplio de temas. En particular, me interesaba entender qué nos dice el manejo de la prostitución, en el sentido más amplio, sobre la interacción entre la sexualidad, la sociedad y el Estado en el Perú en los siglos XIX y XX, y más específicamente lo que nos puede decir sobre lo que llamé 'la cuestión sexual'. Al igual que la cuestión social, un término que abarcó los problemas sociales que supuestamente obstaculizaban el florecimiento de la sociedad industrial (en particular, los problemas que surgieron como consecuencia de la distribución desigual de las ganancias del capitalismo industrial) y las soluciones que se idearon para abordar esos problemas, la cuestión sexual se refiere a los problemas 'sexuales' que se interponían en el camino del florecimiento de la población y las soluciones que se idearon para abordarlos.

Así como la problemática obrera, como demostré en mi primer libro, dio paso a la conformación de un Estado ('the labour state') que buscaba reglamentar y canalizar las relaciones entre el capital y el trabajo, en The Sexual Question propongo que la prostitución, y, las enfermedades venéreas a las que estaba asociada, dieron paso a la conformación de un Estado -entendido no principalmente como una burocracia sino como una forma de poder- que buscó abarcar la cuestión sexual y darle solución. Entiendo entonces tanto el reglamentarismo como el abolicionismo como manifestaciones concretas de ese Estado que se hace visible a través de sus intervenciones en el campo de la cuestión sexual, actuando sobre cuerpos, prácticas y espacios de maneras que disciplinan pero también gubernamentalizan (es, decir, buscan mejorar) a la 'población'. Concretamente, la cuestión sexual evoca las formas en que la sexualidad se convirtió en un problema político en los siglos XIX y XX, un asunto de gobierno ('gouvernement') en el sentido foucaultiano.

Exploro entonces en The Sexual Question cómo las ideas sobre la sexualidad masculina y femenina informaron los intentos de gobernar la prostitución y las enfermedades venéreas. El reglamentarismo, como paradigma adoptado por actores estatales para abordar y dar solución a los efectos de la prostitución sobre el orden público y la salud pública, reflejó pero también construyó interpretaciones tanto de la sexualidad masculina y femenina 
considerada normal y anormal o deseable e indeseable, como del papel del Estado en la regulación de la sexualidad y de su canalización con el propósito de construir la nación e impulsar el progreso nacional. Si bien se movilizaron diferentes tipos de saberes para actuar sobre la sexualidad en diferentes campos en este periodo -como han demostrado Mannarelli, Nécochea y Quiroz, entre otros-, en el caso de la prostitución el saber científico y específicamente médico sobre las enfermedades venéreas demostró ser central para el apoyo al reglamentarismo en el siglo XIX y principios del siglo XX, ya que sirvió para identificar a las prostitutas como el vector principal de las enfermedades venéreas y a los clientes masculinos como su víctima principal. ${ }^{8}$

Los médicos, abogados, científicos sociales, y otros expertos, así como los actores del Estado, preocupados por la cuestión sexual y que operaban dentro de la lógica de la prostitución como 'mal necesario', insistían que debido a que a los hombres les resultaba difícil casarse, y tomando en cuenta el peligro que representaban las perversiones sexuales como la homosexualidad y la masturbación, era imperativo que las prostitutas satisfagan las necesidades sexuales masculinas. Se dedujo que las prostitutas necesitaban ser reglamentadas, lo que implicaba su registro con la policía y su sometimiento a inspecciones médicas regulares, y, más adelante, el desarrollo de un aparato médico enfocado en el tratamiento de las enfermedades venéreas para evitar que contagiaran a los hombres. De esta manera, así como el Estado buscó extender su poder al mundo del trabajo creando leyes, prácticas, e instituciones que buscaban reglamentar las relaciones entre el capital y el trabajo para hacer del obrero un agente del progreso y no un vector de peligro social y político (un proceso, como planteé en The Allure of Labor, claramente racializado en el contexto peruano), vemos cómo en el campo de lo sexual, el Estado también intervino para intentar 'mejorar' la prostitución, reducir su rol como vector de peligros tanto epidemiológicos como sociales y morales, y hacerla compatible, de hecho, integral al proceso de construcción de nación.

En otras palabras, en ambos estudios busqué entender cómo operó la gubernamentalización de la sociedad peruana enfocándome en dos esferas concretas, el mundo del trabajo y el de la prostitución femenina. En la

8 Ver María Emma Mannarelli, Limpias y modernas: Género, higiene y cultura en la Lima del novecientos (Lima: Ediciones Flora Tristán, 1999); Raúl Necochea López, A History of Family Planning in Twentieth-Century Peru (Chapel Hill: University of North Carolina Press, 2014); Lissell Quiroz, "Mettre au monde. La naissance, enjeu de pouvoirs (Pérou, années 1820-années 1920)”, Tésis de "habilitation", Université Paris 8, 2018. 
práctica, en ninguno de los casos se puede hablar de éxito: en ambos libros muestro que las aspiraciones de las elites modernizantes chocaron con la realidad de las limitadas capacidades estatales (tanto cognitivas como disciplinadoras), y la resistencia por parte de los actores sujetos a sus políticas. En el contex to de la construcción del reglamentarismo, la prostituta 'clandestina' emerge como representante de un orden recalcitrante y amenazante, muchas veces de la mano de sujetos peligrosos como los traficantes de blancas y los 'maquereaux'. Por último, frente a la percepción de la incapacidad del orden reglamentarista de reducir el peligro epidemiológico o moral de la prostitución, el abolicionismo emerge como un paradigma alternativo, que busca no 'mejorar' a la prostitución para hacerla integral al mejoramiento de la población, sino, más bien, mejorar, a través de prácticas eugenésicas y de la educación sexual, a la población para hacer de la prostitución algo innecesario.

Este particular abordaje me ha permitido insertar el caso peruano en la historiografía global sobre la prostitución desde una perspectiva que pone en relieve patrones comunes en el manejo de la prostitución pero que también resalta el papel que cumplió la circulación transnacional de ideas y de cuerpos (entre expertos, prostitutas, y 'traficantes de blancas') en el desarrollo de ese manejo (algo que también busqué hacer en The Allure of Labor). Al mismo tiempo, me ha permitido resaltar las especificidades del caso peruano y, en particular, el papel central que cumplió la racialización de la cuestión sexual. Las élites, demuestro, entendieron los peligros de las enfermedades venéreas en formas que reflejaban las racializaciones específicas que dieron forma a la sociedad peruana: culparon a los inmigrantes asiáticos, a principios del siglo $\mathrm{XX}$, de la propagación de enfermedades venéreas en Lima mientras que una sexualidad indígena patológica llegó a ser vista como una explicación de las altas tasas de infección por enfermedades venéreas, a mediados del siglo XX, en el contexto de la creciente migración rural a las ciudades y la expansión de los servicios de salud pública de la capital al resto del país.

Por último, si bien las ideas de las élites sobre la prostitución son un eje central de mi investigación, producto, en parte, del tipo de fuentes a las que tuve acceso, también he buscado mostrar cómo 'la cuestión sexual' fue abordada por una multitud de actores. Cómo las prostitutas negociaron el reglamentarismo es un tema central en la historia de la prostitución que exploro, resistiendo pero también acomodándose. Para algunas mujeres, la mayoría, el reglamentarismo estigmatizó su comportamiento sexual y las marginó socialmente. Para otras, una minoría, el reglamentarismo creó nuevas oportunidades de empleo y para desarrollar una identidad nueva y, en algunos casos, lucrativa. Pero muchos otros actores dieron forma a la 
respuesta a la cuestión sexual, entre ellos médicos y abogados, así como una pequeña cohorte de científicos sociales y trabajadoras sociales, que escribieron sobre prostitución y enfermedades venéreas y trataron de influir en la política; autoridades municipales y estatales, incluidos policías, que implementaron las políticas; e individuos y grupos de interés, desde senadores hasta feministas, desde propietarios de predios hasta anarquistas, desde periodistas hasta el público que escribía cartas al Prefecto quejándose de las 'mujeres públicas' en sus calles.

Estos muchos individuos y grupos, todos afectados por la política frente a la prostitución, buscaron hacerla cumplir, resistirla o alterarla -como en el caso de los individuos y grupos que intentaron derogar el reglamentarismo y promover el abolicionismo, entre los que encontramos médicos y feministas, socialistas y católicos- lo que consiguieron, parcialmente, con la clausura del barrio rojo de Lima en 1956. Entonces, para concluir, más que una historia social de la prostitución, o una historia desde arriba o desde debajo de la prostitución, lo que propone, metodológicamente, pero quizás también epistemológicamente, The Sexual Question es una manera de pensar la historia del 'Estado sexual', es decir el conjunto de intervenciones, desde arriba y desde abajo, que conformaron la respuesta a la cuestión sexual en el contexto peruano. Constituye un intento, similar al que desarrollé en The Allure of Labor, de 'historizar' el Estado -entendido como una forma de poder antes que como una burocracia- como el locus donde se concentran y negocian las agencias de todos los actores sociales. Es, quizás, un intento de pensar la formación del Estado peruano desde las calles de barrio rojo de Lima. 


\title{
Prostitución e historia social del trabajo
}

\author{
Ana Carolina Gálvez Comandini
}

No resulta fácil buscar a las prostitutas en la historia, menos aún buscar los rasgos de resistencia o de autonomía que pudieron haber desarrollado en el ejercicio cotidiano de su oficio. Esa ha sido una problemática metodológica que se ha presentado como una constante para las historiadoras de la prostitución en América Latina.

Si pensamos en las prostitutas de mediados del siglo XIX y de la primera mitad del siglo XX en Chile como sujetos subalternos, es decir, como parte de un grupo que se desarrolló en los márgenes sociales, sin poder político ni reconocimiento social, que no tenía acceso, o este era limitado, a la educación, a trabajos bien remunerados, o a objetos culturales como los libros, el arte, o la música, podremos darnos cuenta que estamos frente a un grupo de mujeres que dejó pocas huellas de primera mano para la historia, básicamente, lo que reconocemos como documentos históricos autobiográficos. ${ }^{9}$

¿Ha sido esto un impedimento para hacer historia de la prostitución en América Latina? Por supuesto que no. Pero nos ha empujado a cambiar el enfoque histórico puesto que hemos tenido que trabajar con fuentes de investigación tradicionales. Por tanto, nuestra lectura de los documentos ha debido ser triplemente acuciosa, primero, haciendo una lectura con perspectiva de género para detectar la presencia de las estructuras de poder y dominación que someten a las mujeres en general; en segundo lugar, una lectura y análisis de los discursos y prácticas que produjeron y reprodujeron, desde esas estructuras de dominación, la estigmatización social de las prostitutas; y en tercer lugar, para buscar la experiencia y la resistencia o autonomía de las mujeres en un contexto donde utilizar la sexualidad como forma para ganarse la vida, como un trabajo, transgredía las lógicas de las esferas separadas, porque las unía, combinaba y entretejía. ${ }^{10}$

Una pregunta que ha rondado esta, y otras investigaciones, es cuánto de resistencia o autonomía hubo en esta acción, en la de prostituirse. Esta es una

9 Ver: Marilynn Wood Hill, Their Sisters' Keepers: Prostitution in New Tork City, 1830-1870 (California: University of California Press, 1993); Nell Kimball, Memorias de una madame americana (España: Editorial Sexto Piso, 2006); Rafael Sagrado, María Villa La Chiquita, Un parásito social del porfiriato (México: Cal y Arena, 1996).

10 Kate Millet, Política sexual (España: ediciones Cátedra, Universidad de Valencia e Instituto de la Mujer, 1995). Primera edición en inglés 1969. 
pregunta que puede tener muchos matices, al igual que las respuestas. No obstante, hay que señalar que las mujeres no nacían prostitutas, ni obreras, ni lavanderas, ni costureras, o sirvientas, entre otros oficios femeninos populares de la época. Las mujeres devenían en estos oficios, muchas veces combinándolos o alternado entre uno y otro. Entonces, vale la pena preguntarse, ¿por qué dentro de un grupo de mujeres que tuvieron la misma experiencia histórica social y material, algunas se dedicaron a la prostitución y otras no?

Las respuestas a estas preguntas no son unívocas ni universales, sin duda, pero desde la investigación histórica para el caso de Chile en el periodo de la reglamentación de la prostitución (1896 a 1925), podemos dar algunas pistas sobre cómo se desarrolló y vivenció la prostitución a este lado de la cordillera, tomando la fuente judicial como principal documento histórico.

Lo primero que tendría que apuntar es que en Chile el negocio de la prostitución no se sustentó a partir de la "trata de blancas", según fue entendido este concepto en la época, es decir, a través del tráfico de mujeres desde Europa hacia otros continentes con fines de explotación sexual. En Chile, las estadísticas sanitarias indican que más del $97 \%$ de las mujeres que se dedicaron a la prostitución eran autóctonas. A pesar de ello, el discurso de la trata de blancas caló hondo en la sociedad chilena, tanto así, que fue una constante en el relato de los médicos, autoridades políticas y de la prensa, donde como sinónimo de prostituta se utilizaba el concepto "esclava blanca", aunque fueran mujeres mestizas nacionales.

Esto ocurría porque el concepto de trata o esclavitud "blanca" remitía, en primer lugar, a la condición indiscutible de sometimiento y explotación sexual que médicos y juristas, entre otros, veían en el oficio de la prostitución. Por tanto, la condición racializada de la prostitución local se cubrió bajo el manto homogeneizador de "esclava blanca", aunque desde el periodo de Conquista el grueso de la población nacional era producto del mestizaje temprano entre indígenas y españoles. Lo "blanco" era (y es) una característica propia de las elites no mezcladas con los sectores populares mestizos. No obstante, suponemos, y aventuramos la hipótesis, de que esa "blancura" también remitía en el imaginario local a la pureza femenina que era mancillada con la prostitución.

Esto llevó a la tarea de investigar los casos judiciales de trata de blancas en Chile, en un periodo que iba desde 1880 hasta 1940 aproximadamente. El objetivo era indagar en las redes de tráfico de mujeres presentes en el país, sus formas de operar y quiénes eran las mujeres "tratadas" o explotadas. Para ello, se revisaron causas judiciales de prostitución, corrupción de menores, 
abandono de hogar, y sumarios de Ley de Residencia (a partir de 1918), principalmente, además de prensa que pudiera dar pistas sobre casos connotados. El resultado fue igual a cero. A la fecha de publicación de este artículo, no hemos encontrado en el Archivo Histórico Nacional de Chile ninguna causa o sumario que evidencie la existencia o presencia de mafias internacionales de tráfico de mujeres que operaran en el país. ${ }^{11}$ Por tanto, nuestra primera conclusión fue que en Chile hubo una reproducción del discurso internacional de la trata de blancas, sin que este se ajustara a la realidad local.

Sin embargo, las fuentes judiciales nos abrieron otro escenario, que vino de la mano de las voces de las propias prostitutas involucradas. La mayoría de ellas declaraba que ejercía el oficio de prostituta porque era mejor remunerado que otros oficios femeninos, sin denunciar o acusar coerción, sometimiento o explotación directa de terceros en esta decisión. En este sentido, las mujeres involucradas en causas judiciales asociadas a prostitución, eran en su mayoría jóvenes entre los 15 y 18 años, edad en la que estaba prohibido prostituirse (pero estaba permitido casarse), figurando en sus relatos siempre acompañadas de otras mujeres, que eran quienes las habrían inducido a la prostitución. Esta inducción a la prostitución tenía que ver con lo que era entendido judicialmente como "corrupción de menores" y tenía relación con "El que, habitualmente o con abuso de autoridad o confianza, promoviere o facilitare la prostitución o corrupción de menores de edad para satisfacer los deseos de otro, sufrirá las penas de presidio mayor en cualquiera de sus grados i multa de ciento a cinco mil pesos". ${ }^{12}$

No obstante, esta inducción podía tener varias formas, y en ellas, según declaraciones de las propias afectadas, muy pocas veces se ejercía el engaño. Es decir, esta inducción o incitación a la prostitución de jóvenes menores de edad, tenía que ver más bien con mostrar un camino o una opción laboral/económica en el comercio sexual para salir de la pobreza u obtener mejores ganancias que en otros trabajos mal remunerados. A pesar de ello, no ponemos en duda que, probablemente, las partes más sórdidas u oscuras del negocio no eran reveladas en la etapa de convencimiento (como, por ejemplo, las enfermedades venéreas, las deudas impagables por ropa, comida

11 No obstante, no cerramos la puerta a que exista la posibilidad de que en la medida que los fondos judiciales se van acrecentando y actualizando, pueda aparecer algún caso.

12 Código Penal de la República de Chile. Libro II, Título VII, Artículo Nº 367 (Santiago: Imprenta de la República, 1874). 
y/o alojamiento, los golpes o malos tratos por parte de las y los regentes del prostíbulo, entre otros).

En este contexto, entre las formas más comunes de ingreso al oficio de prostituta, según los relatos de las propias involucradas, encontramos: 1) ser informadas y convencidas por las meretrices, en los conventillos, hospitales o cárceles donde les tocaba convivir, de que como prostitutas ganarían más dinero que en otros oficios; 2) ser contactadas por dueñas y dueños de prostíbulos, para que fuesen a trabajar a sus casas de prostitución bajo condiciones económicas previamente acordadas; 3) ser engañadas por mujeres mayores llevándolas a prostíbulos y cobrando una comisión por ellas, lo que era considerado como "venta" de mujeres; y 4) "comprando cama" en la casa de una mujer mayor y saliendo de noche a prostituirse en las calles, cobrando el dinero la dueña de casa. Por ende, la segunda conclusión fue que, en el periodo de la reglamentación de la prostitución en Chile, el comercio sexual fue un negocio principalmente de mujeres, donde la información sobre el oficio, apertura de espacios, y el reclutamiento de mujeres jóvenes en el mundo prostibulario estuvo principalmente en manos de las mujeres. ${ }^{13}$

Observando las dinámicas del comercio sexual en los prostíbulos, siempre desde la fuente judicial, la tercera conclusión fue que en Chile existió un tráfico o comercio local de mujeres entre distintos prostíbulos y ciudades. Si bien esta no es una categoría tipificada judicialmente en las fuentes, sino que es emergente, porque ha sido levantada a la luz de la evidencia de la investigación histórica, es una categoría importante porque muestra la dinámica económica y espacial del negocio de la prostitución en Chile, confirmando, además, su distancia con lo que se entendía por "trata de blancas”.

Este tráfico tenía relación con la movilidad local de mujeres nacionales que ya eran prostitutas, entre los prostíbulos de un mismo dueño o entre prostíbulos de distintos dueños, y respondía a criterios comerciales del negocio prostibulario. Estos cambios o rotación de mujeres entre prostíbulos los decidían los dueños o regentes de las casas de tolerancia, y se hacían, generalmente, con el consentimiento de las propias prostitutas a través de una negociación, aunque existen casos en que estas declaraban haber sido “trasladadas” contra su voluntad. Estos traslados tenían que ver con la lógica

13 Y creemos que en el periodo de prohibición de la prostitución y de persecución de las prostitutas, entre 1925 y 1931, se promovió e intensificó el proxenetismo masculino porque las mujeres comenzaron a necesitar y buscar protección de las autoridades sanitarias y de la policía. 
económica de ir renovando la oferta de las mujeres en los prostíbulos, para hacerlos más atractivos a los clientes.

Una cuarta conclusión fue que, siempre que las mujeres se sintieran cómodas en una casa de prostitución, se quedaban por su voluntad, pero cuando se sentían abusadas o maltratadas por los dueños, se fugaban, generalmente a otro prostíbulo donde percibían que iban a recibir mejor pago y trato. Por tanto, la fuga fue otro de los factores de movilidad de mujeres entre distintas “casas de tolerancia”. Esta movilidad por fuga también era económicamente conveniente para ellas, primero, porque se iban sin pagar las deudas que tenían en la casa que dejaban, y segundo, porque al ser nuevas en una casa, tenían más chances de tener clientes. En promedio, las mujeres permanecían en una misma casa entre tres meses y un año.

Por último, la quinta conclusión, fue que la abrumadora mayoría de las prostitutas provenían de hogares tremendamente pobres, donde todas habían ejercido anteriormente, y a muy temprana edad, algún oficio altamente feminizado y mal pagado, como servicio doméstico, costura o lavado, y vieron en la prostitución una oportunidad para salir de la pobreza. Por eso, pensaban que estarían poco tiempo sirviendo de prostitutas porque aspiraban a abandonar el oficio, casarse y tener hijos. Lo cierto es que la mayoría ingresaba soltera y lo abandonaba cuando se casaba, pero al poco tiempo volvía a ejercer por apremios económicos familiares.

Volvemos aquí a retomar la pregunta ¿hubo resistencia o autonomía en estas acciones? Creemos que sí: por salir de la pobreza, por buscar mejores expectativas económicas en la prostitución, y dentro de la misma prostitución, cambiando de prostíbulo, por resistirse al maltrato a través de las fugas, por tener autonomía económica.

La historia social de la prostitución en Chile nos muestra que más allá del discurso de la trata y la explotación sexual, que se popularizó e instaló hegemónicamente desde las elites blancas como una verdad social, la prostitución fue una opción laboral, una estrategia de subsistencia económica para muchas mujeres de los sectores populares.

Sin el afán de romantizar el oficio de prostituta, es relevante señalar que los niveles de explotación y trabajo a destajo en los trabajos productivos y reproductivos de las mujeres en el periodo estudiado, provocó que el oficio de prostituta fuera considerado una opción viable para sostenerse en un mundo donde el valor de lo femenino era relativo a la clase y la raza, y donde la moral sexual imperante en las elites no era aplicable íntegramente a los sectores populares. 
El estigma de prostituta fue parte de un discurso que era mucho más ominoso en las elites que en los sectores populares, donde la prostitución era parte de la vida cotidiana, de los negocios locales, de la economía a pequeña escala, y de las relaciones de sociabilidad barrial. 


\section{En la cama del proletariado. Clase, placer y masculinidad}

\section{Patricio Simonetto}

“En dónde están vuestros intereses más sagrados? ¿En el café, en los prostíbulos, en las diversiones públicas o en el sindicato?” preguntó a sus representados el gremio del dulce. ${ }^{14}$ No es una novedad que además de trabajar los obreros pagaron por placeres sexuales. Como otros contemporáneos, los sindicalistas se consternaron por cómo podrían proteger una sexualidad masculina imaginada como ingobernable de enfermedades venéreas o de “actos homosexuales". José Quevedo, dirigente de la Federación Argentina de Trabajadores de Luz y Fuerza (FATLyF), afirmó que el pago por sexo era la expresión de las dificultades de los trabajadores para contraer matrimonio causadas por sus bajos salarios y precisó que no podían "evitar concurrir al burdel para satisfacer sus necesidades fisiológicas”. ${ }^{15}$

Además de clientes, los varones participaron de diversas formas del mercado sexual: maridos que dependían de los ingresos de sus esposas durante el desempleo estacional, proxenetas y algunas veces, ofreciendo servicios sexuales. También en su calidad de médicos, políticos o jueces, entre otros, participaron del debate sobre cómo debía modularse la prostitución para proteger la salud reproductiva de los trabajadores que poblarían la Argentina.

Mi libro El dinero no es todo. La compra y venta de sexo en la Argentina del siglo $X X$ estudia las diversas formas de vender, comprar y mediar sexo, las prácticas cotidianas, las interpretaciones cambiantes de las y los actores; y, las políticas estatales que lo modularon. Atraviesa los quehaceres de los "tratantes de blancas" a las "ruteras" que atendieron camioneros, desde las mujeres que vendieron servicios sexuales cuando la limpieza de casas no alcanzaba hasta las obligadas a pagar coimas al comisario para evitar la cárcel, desde los adolescentes que pagaron para "debutar" hasta los taxiboys. ${ }^{16}$

14 Anónimo, "El sindicato”, Unión Confiteros, 4 (1917): 1. Este artículo se inscribe en el proyecto de investigación "Memorias disidentes de la masculinidad en España e Hispanoamérica” (PID2019-106083GB-IOO).

15 Quevedo, José. El sindicalismo y el problema de la prostitución (Buenos Aires: Laboratorio Social Argentino de la Peña Sindicalista, 1952).

16 Patricio Simonetto, El dinero no es todo: compra y venta de sexo en la Argentina del siglo XX (Buenos Aires: Biblos, 2019). 
Mi investigación recorre un periodo que va desde 1924 a 1984 en el que se destaca la abolición de los burdeles patentados (1936). Este recorte enfatiza que, a pesar de la alternancia entre gobiernos civiles y militares, de 1930 a 1984 primó la continuidad de prácticas punitivas moralistas que afectaron a prostitutas, disidentes sexuales, jóvenes y pobres. Además, utiliza una escala que interconecta espacios transnacionales, regionales y locales, interconecta latitudes heterogéneas y se ocupa de zonas periurbanas o rurales para ampliar nuestro conocimiento sobre agentes sociales relegados por una historiografía urbano-céntrica. ${ }^{17}$ Para ello trabajé con un corpus de expedientes judiciales, legajos de la cárcel y cartas, entre otros documentos.

Podría recorrer diversos cruces entre historia de la prostitución y del trabajo. Las causas judiciales me presentaron múltiples formas en que los mercados sexuales y laborales se conectaban: estibadores sostenidos por el trabajo sexual y de lavado de sus esposas en temporadas de desempleo, padres que colocaron a sus niñas como domésticas, algunas de las cuales huirían para ofrecer servicios sexuales a trabajadores de diversos rubros, viajeras que seguirían los ciclos de cosechas, obreros que denunciaban a mujeres por contagiarles enfermedades venéreas, entre otras. Redes que ponían a prueba universos separados por los registros morales con los que imaginamos a les trabajadores pero que en sus testimonios unían placer, productividad y reproducción social. A través de sus camas se caía ante mí la frontera imaginaria del proletariado. ${ }^{18}$

Como investigador de la comunidad LGTBIQ me resultó difícil identificarme con los testimonios que brotaban de los documentos, con la exaltación de las felatios o la celebración entre amigos por haber durado cuatro minutos en una cama. Una distancia epistemológica, quizás desapercibida para otros investigadores, que me permitió interpretar cómo se materializó la heterosexualidad en Argentina. Un punto de contacto con los crecientes cruces entre masculinidad y culturas trabajadoras con acento en su sexualidad. ${ }^{19}$ Me propuse revertir una dirección tradicional de la historia de

17 Juan Suriano, “¿Cuál es hoy la historia de los trabajadores en la Argentina?”, Mundos do Trabalho 1, no. 1 (2009): 27-50.

18 Lara Putnam, The company they kept: migrants and the politics of gender in Caribbean Costa Rica, 1870-1960 (North Carolina: University of North Carolina Press, 2002).

19 Sol Calandria, "Cómplices y verdugos: masculinidades, género y clase en los delitos de infanticidio (provincia de Buenos Aires, 1886-1921)", História (São Paulo) 38 (2019); Florencia D'Uva, "Masculinidades obreras en los ferrocarriles: fuerza física, riesgos y responsabilidad profesional en la Argentina de principios del siglo XX”, Revista Estudios del ISHiR, 9, 25 (2019). 
la sexualidad que se focalizó en la “anomalía” para pensar la espesura de sexualidades dominantes en tiempos y espacios concretos.

Fiel a la economía de palabras, en este texto compartiré reflexiones sobre el consumo de servicios sexuales como articulador de masculinidades trabajadoras. A pesar de su relevancia en los documentos, la historiografía prestó poca atención a esta actividad como parte del universo del ocio de los trabajadores. ${ }^{20}$ Entiendo que el hecho de que las visitas al burdel no captaran la misma atención que los partidos futbol o las tardes en el bar se apoyó en una moralización de la noción de clase que tendió a separar aspectos íntimos de públicos, como también, a ignorar dimensiones que podrían opacar un juicio moral positivo de los subalternos.

Primero, estudié la construcción política del derecho a pagar por sexo. La abolición de burdeles patentados ocasionó la reacción de quienes consideraron que atentaba contra la potestad de los varones por acceder a servicios sexuales. Decenas de militares, como el joven Juan Domingo Perón, buscaron refrendar esta representación política. En consonancia con médicos de la época, entendían a la sexualidad masculina como incontrolable e irracional. En particular, los trabajadores fueron presentados como los más vulnerables a los efectos "perniciosos" de la abstinencia como consideraban a las dolencias venéreas, el onanismo o la homosexualidad.

Los gremios se avocaron a debates entre quienes defendían el sistema de burdeles patentados como emanación del derecho al consumo de sus afiliados varones y quienes entendían a su abolición como la garantía contra la explotación de las mujeres trabajadoras entendidas como sujetos pasivos víctimas de la miseria. Debates que derivaban en pleitos, como el sindicato de taxistas que se dirigió al Ministro del Interior para quejarse de la “arbitrariedad con la que la policía aplica la ley 12.331". Hacían notar que "el justicialismo de Perón y de la mártir del trabajo Eva Perón” invitaba a una "felicidad que siempre debía moverse en el marco de una estricta moral sin

20 Donna J. Guy, Sex \& danger in Buenos Aires: prostitution, family, and nation in Argentina, vol. 1 (Nebraska: University of Nebraska Press, 1991); Cristiana Schettini Pereira, "Lavar, passar e receber visitas: debates sobre a regulamentação da prostituição e experiências de trabalho sexual em Buenos Aires e no Rio de Janeiro, fim do século XIX”, Cadernos pagu, 25 (2005): 25-54; Pablo Ben, Male sexuality, the popular classes and the state: Buenos Aires, 1880-1955 (Chicago: The University of Chicago, 2009); María Luisa Múgica, La ciudad de las Venus impúdicas: Rosario, historia y prostitución, 1874-1932 (Rosario: Laborde Editor, 2014). 
habilitar el libertinaje” pero reclamaban se dejara de castigar a sus afiliados acusados de proxenetas por trasladar "prostitutas". ${ }^{21}$

Segundo, mi mayor contacto llegó por la judicialización del mercado sexual. Los expedientes rebozaban de testimonios de trabajadores que en la confianza masculina con la policía desplegaron narrativas escandalosas sobre sus aventuras sexuales. Como testigos exaltaron su masculinidad generalmente en perjuicio de la detenida que pasaría días, meses y a veces años en la cárcel. Los testimonios de jornaleros, estibadores u obreros sobresalían por sobre los de las elites locales quienes tenían mayor poder para evitar esos trámites, además, recurrieron a burdeles especiales con los que buscaron distinguirse de sus empleados.

Tercero, me llamó la atención que los varones generalmente compraban servicios sexuales con amigos. Pagar por sexo era un ritual que ponía en juego detalles como la espera, el uso del espacio de trabajo para concretar encuentros, la circulación de objetos y conocimientos. Esta actividad grupal pero siempre individual, movilizaba una trama cultural heterogénea con la que eran mesurados por sus amigos. Esto nos permite explicar cómo se interconectaban el ser varón, trabajador y heterosexual en sus vidas diarias. Para ello apelaron a diversos espacios y formas de asociación con las que se constituyeron como demandantes de sexo pago. En estas situaciones, para los varones que debutaban podía ser el acceso de una masculinidad mayúscula: una acreditación frente a sus pares generalmente mediados por jerarquías generacionales. También una confirmación de un deseo que, legitimado frente al supuesto de una pertenencia natural, revalidaba sus privilegios.

Cuarto, el lenguaje de los trabajadores se valió de su cuerpo como metonimia de la virilidad. Al declarar pusieron en juego narrativas que mediaron sus nociones corporales, la producción de una interpretación plebeya del mandato de masculinidad dominante que adquiría fuerza en prácticas cotidianas. En sus testimonios utilizaron distintas metáforas que podríamos agrupar en dos referentes: su genitalidad y la mujer objetada. Ante la ley, se definieron como sujetos frente a objetos pasivos depositarios de su necesidad bestial y natural. Sus cuerpos se definieron como entidades activas y productivas de una sexualidad que debía ser canalizada. Ambos se articularon en una narrativa que resaltaba las capacidades activas de sus cuerpos y la virulencia con la que estos efectuaron el acto.

21 Archivo General de la Nación, Archivo Intermedio, Informe Ley 12331, caja 119, $\mathrm{N}^{\circ} 135,1953$. 
La cultura sexual plebeya apeló a la genitalidad como centro para destacar la penetración de otro u otra como fuente de jerarquización. ${ }^{22}$ En 1954 Luis de dieciséis años, un jornalero rural, denunció a Josefa por contagiarle una dolencia venérea. Relató que unas horas después de tener relaciones, mientras sus compañeros de trabajo lo esperaban en la puerta del rancho sintió "una fuerte hinchazón y unos granos en la cabeza del bicho”, agregó que no usaron "forro" sino que lo hicieron a "la criolla (...) le eché solo un polvo". El joven afirmó sentirse avergonzado por lo que ocurría en sus genitales. Ángel, el mayor del grupo de jornaleros que asistió a esa casa, declaró que no estuvo allí más que "el tiempo necesario para echarse un fierrazo", que no usó "ningún forro con el fusil”. ${ }^{23}$

Las metáforas con las que los varones hablaron de sus genitales tendieron a presentarlos como instrumentos violentos y salvajes. La falta de precauciones preventivas se explicaba porque practicaban sus relaciones en un modo tradicional, es decir, bajo los principios de la naturaleza. La idea de criollo estaba asociada con la cercanía a la que el ideal de nación se hacía del agro, de lo natural y por lo tanto de lo bestial-violento. La enunciación bélica del pene como aquel que no tenía protección para penetrar y la exaltación de aquella falta contenía que la inquietud por la salud era propia de la delicadeza femenina y no de una virilidad ingobernable. El placer del contacto piel con piel reforzaba el imaginario de la naturaleza incuestionable de la masculinidad como centro del placer. Aquella enunciación era la apoteosis de un ser viril según la cual en la intimidad era el varón quien decidía sobre la necesidad o no de una práctica sanitaria. La reivindicación de ese acto como decisivo de su virulencia viril era motivada por una sexualidad imaginada en términos androcéntricos.

Las referencias sobre las mujeres implicadas y las metáforas con las que destacaron su virilidad a través de sus genitales no son intervenciones culturales sobre una superficie escéptica natural. La referencia a la teatralidad del proceso de demanda, sobre cómo y por qué estos varones agenciaban el consumo de servicios sexuales en grupo remiten también a la potencial pregunta sobre cómo se materializa el género. En este camino sinuoso, la experiencia deja de ser la entidad transparente que revalida una noción ontológica de las identidades, donde ser varón y heterosexual interactúa con la clase.

22 Pablo Ben, "Plebeian masculinity and sexual comedy in Buenos Aires, 18801930", Journal of the History of Sexuality 16, 3 (2007): 436-458.

23 Departamento Histórico Judicial Sur, Carpeta 516, folio 1470, 1954. 
El dinero no es todo es una invitación a trabajar en los cruces entre la sexualidad y la clase. Una invitación a pensar los límites morales con los que representamos y se representaron les trabajadores. Para extender una imaginación histórica que desdibuje las distancias entre la cama, la fábrica, la hacienda, el puerto o la cocina. 


\title{
Os arquivos não falam, os arquivos respondem! Reflexões de uma trajetória a posteriori
}

\author{
Beatriz Kushnir
}

As pesquisas podem ter início por inúmeros motivos. Essa se instaurou pelo insuportável incômodo que as proibições me causam. Quando, em fins da década de 1980, resolvi perguntar quem seriam estas moças, as respostas eram vagas e negativas. As polacas são o tema de minha dissertação de mestrado, e era a atividade de prostitutas, cáftens e cafetinas, entre eles judeus, que traziam mulheres da Europa Oriental para as Américas e o Oriente. As mulheres judias conhecidas como polacas, chegavam, principalmente, a Xangai, Nova York, Buenos Aires, Montevidéu, Córdoba, Santiago, Rio de Janeiro, Santos, São Paulo etc., por uma rota de tortuosos caminhos. Instalando-se no baixo meretrício, ocuparam as áreas do Mangue e Lapa, no Rio de Janeiro, do Bom Retiro em São Paulo, La Boca, em Buenos Aires; e assim por diante.

Inicio com uma ponderação do falecido tão precocemente, o escritor Moacyr Scliar. Ao mapear uma história dos judeus, de seus primórdios à emigração da Europa Oriental para as Américas, separa um capítulo para o tráfico de escravas brancas e "profetiza”: “(...) exorcizar demônios é uma tarefa difícil. (...) Mas deve ser feito, e o primeiro passo é, como o sabiam os exorcizadores, chamar os demônios pelo nome”. ${ }^{24}$

Demônios, fantasmas, silêncios e segredos são os invólucros que rondaram as tentativas de uma possível abordagem da temática. Acabaram? Infelizmente não. Renasceram. Bibliografias recentes têm nos títulos sinônimos à impuros e degenerados, demonstrando o ciclo conservador que vem se instalando no mundo e que volta a atingir essa experiência migratória. Mais de quatro décadas de análises estão retrocedendo... Resistir vai além da academia, para mim. Há a impressão de que as rugas que estas mulheres produziram em uma parcela da comunidade judaica, regressam e as tentam enclausurá-las na clave do pecado.

Minha análise repensa a questão ao vincula-la à densa problemática da construção de uma identidade judaica em seu conceito moderno. Não analiso a prostituição e a sexualidade que absorveu médicos, juristas e policiais na virada do século XX nas principais capitais do país, seguindo uma tendência

24 Moacyr Scliar, A Condição Judaica: das tábuas da lei á mesa da cozinha, $2^{\mathrm{a}}$ ed. (Porto Alegre: L\&PM, 1985). 
mundial de normatizar condutas e controlar o espaço público. Reconstituo como um determinado grupo, marginalizado na sua dupla condição de imigrante e vigiado pela Polícia, viabilizou mecanismos de autoproteção que lhes permitiram romper a exclusão religiosa e social na qual os legisladores do país e os dirigentes das comunidades judaicas os colocaram. Não os percebo como vítimas sociais da miséria e dos processos migratórios. Apreendo seus mecanismos de sobrevivência e de construção de uma identidade social positiva.

Os homens e mulheres envolvidos na atividade do tráfico e no mercado da prostituição estrangeira, e que eram de origem judaica, obviamente não construíram laços de solidariedade e sociabilidade com as comunidades judias nas cidades onde coexistiram. Foram percebidos sempre como transgressores, estabelecendo, pela oposição de condutas, o lado bom e mau da comunidade. Algo compreensível vindo de imigrantes que fugiam de perseguições religiosas e queriam a todo custo construir uma imagem positiva na nova pátria imigrada. Entretanto, em um ponto estes dois lados da comunidade judaica se encontravam: a dura condição de estrangeiro lhes era comum.

Esse mecanismo de separação gerou no grupo excluído um artifício de sobrevivência: a necessidade de organizar instituições - sociedades de ajuda mútua - que refizessem uma vida social e religiosa e lhes permitissem uma identidade pelas práticas coletivas. Foi para encontrar tais traços que, desde o início, se buscou localizar fontes produzidas pelos homens e mulheres envolvidos nesta atividade e abandonar leituras de terceiros acerca de sua existência. Objetivou-se achar tais pessoas e suas histórias particulares, rompendo com as máscaras sociais previamente estabelecidas.

Esse trabalho se vinculou a uma História da Cultura ou uma tendência Etnográfica da História, ${ }^{25}$ buscando a fala do grupo sobre si e partindo da premissa que esse deixou registro. Algo por si só intrincado e raro, pois, lidou-se com pessoas marginalizadas que ou tem seu passado "alterado" nas narrativas de descendentes pouco a vontade com suas "origens", ou não têm possibilidades de preservar seus trajetos.

Na pesquisa localizei o histórico de cinco sociedades fundadas por homens e mulheres judeus envolvidos com a prostituição: a do Rio de Janeiro -

25 Robert Darnton, O Grande Massacre de Gatos (Rio de Janeiro: ed. Graal, 1986);

Robert Darnton, O Beijo de Lamourette. Mídia, cultura e revolução (São Paulo:

Companhia das Letras, 1990); Carlo Ginzburg, "Sinais: mitos de um paradigma indiciário” em Mitos, emblemas, sinais - morfologia e história (São Paulo:

Companhia das Letras, 1989), 143-79. 
Associação Beneficente Funerária e Religiosa Israelita (abfri)- fundada em outubro de 1906; a de São Paulo -Sociedade Feminina Religiosa e Beneficente Israelita (sfrbi)- fundada em 1924; a de Santos -Sociedade Beneficente e Religiosa Israelita de Santos- fundada em 1930; a de Buenos Aires -Sociedade de Ajuda Mútua Zwi Migdal-fundada em 1906; e a de Nova York - The Nerw York Independent Benevolant Association- fundada em 1896. Entretanto, só as duas primeiras são objeto do texto, pois são delas os documentos originais examinados: atas, estatutos, livro-caixa, material iconográfico e depoimentos de funcionários e/ou descendentes.

Perceber o fluxo e do comércio da prostituição estrangeira por uma ótica do seu mundo privado não negligenciou uma análise do contexto mundial que cercou a questão. Não restringi a reflexão à ideia de uma rede de tráfico e de homens que roubam mulheres e as enganam. Congreguei um conjunto de relações que cada grupo estabeleceu entre si, visando construir uma rede de associações com base na solidariedade entre os que têm uma condição social marginalizada. Para tal, as reflexões do sociólogo francês Michel Maffesoli acerca da sociabilidade nas Máfias é percebida na distinção de sua organização criminosa e de uma "atitude máfia", com base na ajuda mútua total entre os pares. Esta atitude realiza-se na noção de "família", que protege o grupo e geralmente está envolvida nas relações entre imigrantes para preservarem sua singularidade e originalidade. E foi esta noção que dirigiu as reflexões. ${ }^{26}$

O tráfico de brancas foi alvo da preocupação de governos e de entidades filantrópicas. Os próprios homens e mulheres envolvidos na prostituição estrangeira registraram sua história, na tentativa de sair desta condição marginal, estabelecendo laços associativos e autoprojetores. Ao apreender os 62 anos de existência da sociedade carioca e dos 44 anos da entidade paulista, se compreende os diferentes caminhos que os trouxeram em seus processos migratórios. Suas necessidades de sociabilidade e solidariedade os fizeram fundar, em cada cidade onde se estabeleceram, sociedades de ajuda mútua. Semelhantes a outros grupos imigrantes, as polacas e seus amigos e/ou maridos constroem uma vida comunitária. Na dimensão organizacional e valorativa deste cotidiano que este trabalho está centrado.

O contato com uma documentação original e com pessoas que vivificaram o dia-a-dia do grupo de polacas cariocas - ou porque nele trabalharam, ou porque são seus descendentes -, permitiu uma visão "de dentro" e a quebra

26 Michel Maffesoli, "La Maffia. Note sur la socialite de base" Cahiers

Internationaux de Sociologie 73 (1982): 363-68; Michel Maffesoli, "La Prostitution comme 'Forme' de Socialité" Cahiers Internationaux de Sociologie 78 (1984): 11933. 
de imagens estereotipadas. Fiz com que os depoimentos de Zelda e Celina filhas de uma mulher ligada à abfri, do Rio -, e o Sr. O - Contador da entidade - percorressem o texto.

Minha reflexão centra-se neste grupo marginalizado para discutir a construção de identidade em suas múltiplas possibilidades. Este conceito está longe de ser um dado. Existe e se constitui nas possibilidades de um construído, vivenciado nas práticas do coletivo. ${ }^{27} \mathrm{~A}$ experiência das polacas se torna tão rica ao reconstruírem seus pactos com o cultural do qual eram frutos. Vivenciaram suas identidades religiosas mesmo estando fora do grupo comunitário tipo com o oficial. Os laços de solidariedade e sociabilidade sustentaram uma identidade coletiva socialmente definida como positiva.

Um sentido aproxima as trajetórias das duas sociedades tratadas: sua noção assistencialista e de caridade entre os iguais. Fundar sociedades de ajuda mútua significava, na prática, comprar terrenos para construção de cemitérios, manter serviços religiosos em dias sagrados e auxiliar os membros doentes e idosos. Duas diferenças básicas são registradas. Primeiro, a maneira particular que cada grupo se adaptou às suas especificidades internas nas cidades onde existiram. A entidade paulista é, desde sua criação, uma sociedade feminina marcada pela competição, disputa por liderança e fôlego para construir e vivenciar uma vida comunitária. Já a entidade carioca, dirigida ora por homens ora por mulheres, pode ser mais bem percebida como uma irmandade centralizada em poucas figuras que tentou sempre superar crises, dando a impressão de um eterno recomeço e restruturação para levar a cabo seus objetivos. A imagem de irmandade está na auto intitulação das irmãs do "Chesed shell emes" - ou da "Caridade de Verdade", aquela que não busca recompensa. Essa inscrição está na lápide da Primeira Irmã Superiora, que faleceu em 1932.

Existe o movimento de dentro do grupo para fora e seu inverso. Um exemplo encontra-se nos processos de adaptação das associações quando a "tolerância" à prostituição diminui, o que levou à migração de polacas paulistas para o Rio de Janeiro nos anos 1950. Os processos de perseguição e de desarticulação total destas entidades são situados dentro de um momento particular. A vivência de prostitutas judias e de um fluxo organizado que as trazia para abastecer mercados receptivos é inscrito em uma determinada coordenada espaço-temporal. Seu fim e o término de suas vidas esgotam o fato como

27 Celso Lafer, "Identidade individual e identidade coletiva: o judaísmo e os dilemas da modernidade”. Ensaios Liberais (1991): 183-87. 
possibilidade histórica. A entidades existem e perdurando de 40 a 60 anos, enquanto as polacas estão vivas e necessitam de laços de solidariedade.

No diálogo entre o grupo e o mundo exterior, se destaca o papel e a estrutura da comunidade judaica em cada cidade onde coexistiram com as polacas. Em São Paulo, a comunidade permitiu, por um lado, que fossem amparadas no asilo, e não permitiu, por outro, a manutenção de suas identidades quando do translado dos corpos do Cemitério Israelita de Santana/Chora Menino para o Cemitério Israelita do Butantã. Nos anos de 1970, após a desestruturação física da entidade paulista, com a velhice de seus membros, o cemitério da sociedade foi desapropriado pela prefeitura dado o seu estado de abandono. Os corpos não reclamados por parentes foram removidos para o cemitério israelita da cidade e só em 2000, as identidades foram colocadas em cada lápide. No Rio, a comunidade auxiliou umas poucas sociais e sócios da abfri em seu hospital. Cuida do Cemitério Israelita de Inhaúma, o primeiro cemitério judeu da cidade, fundado em 1916 e que pertenceu a associação das polacas cariocas. Os Decretos $n^{\circ}$ 28.463, de 21/9/2007 e $n^{\circ} 32.993$, de 27/10/2010 registram o tombamento pelo Patrimônio Cultural da Prefeitura do Rio, o resguardado enquanto o espaço de sepultamento dos sócios e sócias da abfri.

Estas práticas demonstram as dificuldades que a temática provoca em certos setores da comunidade judaica. Expõem os graus de organização e de construção de uma estrutura comunitária e assistencialista nas diferentes comunidades judaicas no Brasil, seus limites e possibilidades. Por serem percebidas como transgressoras de uma ordem - mais por circunstância do que por escolha -, muitas não se deixam cair na armadilha da exclusão. Realizaram seu pertencimento pela via associativa religiosa. Suas existências foram marcadas pela ação, consciente ou não, de conservação, transposição e produção de imagens que ordenassem seus mundos privados, tornando o espaço comunitário a possibilidade de um muro protetor.

A reelaboração do passado coletivo - via costumes e tradições - lhes deram a possibilidade de uma vida fora dos limites da condição marginal. Reelaboraram suas histórias construindo-as e reconstruindo-as nas necessidades do seu presente e engajaram-se em uma herança comum. As sociedades não podem nem devem ser compreendidas como um lugar de resistência tout court. Compreendendo que fé não tem dono, exerceram no cotidiano a união entre ideia e ação. Na maioria dos casos morreram muito pobres.

A história da história das polacas foi desvendar quem seriam estas mulheres e apreender suas trajetórias, percebendo que, dentro do panorama da 
imigração, várias biografias se complementam, não havendo um perfil único de imigrante. Apreender as polacas é uma forma de dissipar fantasmas e fantasias e compreender nas suas trajetórias, estratégias de construção de identidades religiosa e cultural.

Esse trabalho foi, por muitas vezes, um costurar de lembranças, de memórias. Encontrar descendentes daquele universo dispostos a abrir seus corações, me fez, certamente, uma ouvinte privilegiada. Na elaboração do mesmo, tentei fazer jus a riqueza destes depoimentos, e realizei o que mais queria: deixar que elas contassem suas histórias. Ao um possível fim formal do trabalho - a publicação da dissertação em livro -, compreendi que: a) só pude construir essa reflexão porque tinha perguntas e assim, os documentos (arquivos) chegavam ou eram localizados; b) que o trabalho não tinha terminado e que o tema exigia de mim além da postura reflexiva, a participação e a ação numa militância de combate. E são ambos os papeis que tenho realizado, desde então. 